\title{
Open-distance electronic learning environments: Supervisors' views on usability
}

\author{
Sewisha Lehong \\ University of South Africa \\ Johannesburg, South Africa \\ lehons@unisa.ac.za
}

\author{
Judy van Biljon \\ University of South Africa \\ Johannesburg, South Africa \\ vbiljja@unisa.ac.za
}

\author{
Ian Sanders \\ University of South Africa \\ Johannesburg, South Africa \\ sandid@unisa.ac.za
}

\begin{abstract}
Students in the open-distance and electronic learning (ODeL) environment often work in isolation and face challenges in accessing knowledge resources, especially when conducting research. To support these students in succeeding with their studies, the learning management system (LMS) needs to be usable; this implies the attributes of effectiveness, efficiency and user satisfaction. The purpose of this study is to propose usability guidelines specifically focused on the requirements for a learning management system in the context of ODeL honours research projects. The study is novel in exploring the supervisors' view of the usability requirements of the LMS. Based on a pragmatic worldview, this study is guided by the design science research (DSR) methodology. The initial set of usability requirements was abstracted from the literature and used as the basis for the LMS evaluation. Usability testing of the LMS was followed by heuristic evaluation, post-test questionnaire and interviews. All evaluations were done with the supervisors as participants. The contribution of the study is the refined usability guidelines based on the triangulation of the findings from the different usability evaluations conducted on the same ODeL LMS.
\end{abstract}

Keywords-Open-distance learning, learning management systems, heuristics evaluation, usability testing, eye-tracking.

\section{INTRODUCTION}

$\mathrm{O}^{\mathrm{p}}$ PEN-DISTANCE learning (ODL) focuses on removing the barriers to access learning, provision of flexible learning, student-centredness, supporting students and constructing quality learning programmes with the expectation that students can succeed [1]. The use of online technologies in ODL allows institutions to deliver, facilitate, and improve the teaching and learning to students $[2 ; 3 ; 4 ; 5 ; 6]$. ODL institutions use technology for student support, interaction, information sharing and access to resources amongst students, staff, and institutions $[4 ; 7]$. Educational online technologies for social collaboration assist in learning through discussion forums such as Facebook, YouTube, and WhatsApp. If these technologies are integrated with the learning management systems, they may help to improve student success. Previous studies on the usability of learning management systems (LMS) have considered the students' perspectives [8; 21;22; 28; 29]. However, the supervisor's perspective on the usability of LMSs in open-distance electronic learning (ODeL) [9] has not been investigated and described in-depth. That presents a gap in the literature since the supervisors have relevant expertise pertaining to students' information content needs. This study addresses that gap by considering the following research questions:

1) What are the existing usability guidelines for ODeL learning management systems?

2) What are the supervisors' perspectives for the usability guidelines of an ODeL learning management system?

The paper is arranged as follows: Section II provides a literature review discussing terminologies, concepts and characteristics within the scope of this study. Section III presents the research design and methodology applied in this study while Sections IV, V, and VI provide the discussion of the findings and conclusion, respectively.

\section{LITERATURE REVIEW}

\section{A. Open Distance e-Learning Paradigm}

Distance learning is a process where teaching a diverse range of students located at different places (i.e. students are physically separated from their institution and lecturers) is facilitated by the use of technologies $[1 ; 7 ; 10]$. Open learning is an approach to teaching and learning with a strong emphasis on flexibility and student-centredness [1; 10 ; 11]. E-learning is the learning process facilitated, enhanced, and supported with the use of information and communication technology (ICT) regardless of time and place of access.

\section{B. Learning Management System}

ODeL institutions use learning management systems (LMSs) to facilitate teaching and learning. LMS is an integrated software system which assists with online management and delivery of educational courses and content, student learning, reporting and administration [13]. The implementation of an LMS in ODeL institutions assist students to communicate with their lecturers, peers, faculty, and administration. LMSs incorporate advanced technologies, tools and features for managing and facilitating the learning activities. Examples of tools include content management, communication, student evaluation, assignment submission, library services and resources. While technologies used to support ODeL students include multimedia, video, conferencing, audio,

ISBN 978-1-5386-7365-2/19/\$31.00 (C2019 IEEE 
mobile phone short message services (SMSs), multimedia messaging services (MMSs), social media, chats and discussion forums [11].

\section{Usability}

Usability is defined as "the extent to which a system, product, or service can be used by specified users to achieve specified goals with effectiveness, efficiency, and satisfaction in a specified context of use" [14:2]. Usability is essential for example, in increasing user satisfaction, contributing to meeting expected targets, providing social and economic benefits for stakeholders and reducing costs. Attributes used to measure usability are its effectiveness, efficiency and satisfaction. ISO 9241-11 [14] describes the usability measures as follows:

- Effectiveness - "refers to the accuracy and completeness with which users achieve specified goals".

- Efficiency - "refers to the resources used in relation to the results achieved".

- Satisfaction - "refers to the extent to which the user's physical, cognitive and emotional responses that result from the use of a system, product or service meet the user's needs and expectations".

Usability plays an important role towards student success in interaction with the LMS. The lack of usability tends to make users spend time learning how to use the system rather than productively using it. In ODeL institutions usability is even more important since students work in isolation; often also under time and other resource constraints. There are various tools and techniques for evaluating the usability of systems in the literature. In this study, we will use heuristic evaluation (HE) as discussed in the next section.

\section{Heuristic evaluation method}

Heuristic evaluation (HE) is a usability inspection method used by the expert evaluators to find usability problems $[15 ; 16 ; 17 ; 19]$ guided by a set of guidelines [19; 31]. The HE was originally developed by the champion of usability engineering, Nielsen, in 1990 with the aim to improve the usability of systems [19]. HE is considered to be a less expensive usability evaluation method since it does not require extensive time for planning, and employs a smaller number of experts to test the interface than actual users $[15 ; 16]$. The evaluators are expected to be familiar with the system under investigation. During evaluation, each expert evaluates the interface independently using the heuristics to determine the potential usability issues [15; 16; 20]. Heuristic evaluation (HE) is viewed as flexible, cost-effective and relatively easy to execute. The results of
HEs rely heavily on evaluators' expertise and background. The usability evaluation for this study was based on ten (10) original heuristic evaluation guidelines developed by Nielsen.

\section{E. Heuristic evaluation as a usability method for evaluating learning management systems}

This study used heuristic evaluation to evaluate the usability of an LMS with expert evaluators. Different authors including $[16 ; 20 ; 21 ; 22]$ have used this method to evaluate e-learning and LMS platforms. Although HE is regarded as a discount method to employ, it is a reliable and efficient method that can point out potential usability problems [16]. According to Nyang'or, De Villiers, and Ssemugabi [22] the "usability of e-Learning system involves both technical and pedagogical usability". In this study, we collected usability evaluation guidelines from the literature, modified; and adopted 10 Nielsen heuristics to suit our objectives. Our heuristic evaluation criteria are based on user interface and educational guidelines. The proposed usability guidelines are provided in table III (see Appendix).

\section{RESEARCH DESIGN AND METHODOLOGY}

\section{A. Research Design}

This study deploys the design science research (DSR) strategy to evaluate the proposed usability guidelines. DSR $[24,25]$ is a strategy used to design and evaluate artefacts with an aim of improving those artefacts. The design and development of DSR artefacts may produce constructs, models, methods, and instantiations as the research contribution or outcomes [23]. DSR is appropriate for this study because it involves a rigorous process to evaluate artefacts, in this case, usability guidelines. We evaluated the usability guidelines by comparing the findings of the usability testing, SUS questionnaire, heuristic evaluation of the MyUnisa LMS and interviews with the intention to solve the problems identified. Triangulation was used to identify usability problems and evaluate the guidelines. The triangulation was performed by comparing the findings from the usability testing, SUS questionnaire (descriptive statistical analysis) and interviews (thematic analysis).

We have followed the design science research (DSR) process that consists of the following six phases. Phase 1 introduces the research problem, Phase 2 provides the objectives of the study, Phase $\mathbf{3}$ is the creation stage of the usability guidelines for LMS based on a literature review, Phase 4 constitutes the demonstration of the artefact (guidelines) as a heuristic evaluation tool, Phase 5 involves the evaluation of the artefact through triangulation of the findings (using multiple methods to develop an 
understanding of the phenomena), Phase 6 involves the communication of the research, in this case, this peerreviewed publication. Our contribution to research is the usability guidelines as a framework to advance the body of knowledge on usability and LMS. Contributions based on iterative improvements and communication of the research is fundamental to DSR $[24 ; 25 ; 26]$.

Participants were the supervisors for honours research students from the University of South Africa. The University of South Africa, the largest ODeL institution in Africa is located in the Gauteng province of South Africa. This study focuses on the school of computing (SoC) which offers research qualifications to honours, masters and doctorate students. All postgraduate students use the myUnisa LMS to access study material and services. For the purpose of this study, we will only focus on supervisors for honours students. The honours degree is a two years postgraduate degree offered to students who have completed a bachelor's degree, advanced diploma, or granted permission through recognition of prior learning (RPL). The honours degree programme consists of eight modules including a research proposal and a research project.

This study started by conducting the pilot study with three participants in order to validate the process of collecting data. Few changes were applied from the results of the pilot study such as changing the order of usability testing tasks. Nine supervisors participated in the study and are considered the experts in educational content and usability of a learning management system. As can be seen from table I, there were six males and three females. That includes two participants with PhDs and at least six years of supervision experience each, two more supervisors with $\mathrm{PhDs}$, one with at least 5 of experience and the other one with at least 2 years of experience, five supervisors with MSc's, one with at least 3 years of experience and four supervisor with less than two years of experience.

\begin{tabular}{|l|l|l|}
\hline \multicolumn{3}{|c|}{ TABLE I } \\
\multicolumn{2}{|c|}{ DEMOGRAPHIC DATA } \\
\hline Age & Male & Female \\
\hline Less than 40 & 4 & 0 \\
\hline $41-50$ & 2 & 2 \\
\hline Above 50 & 0 & 1 \\
\hline Total & 6 & 3 \\
\hline
\end{tabular}

\section{B. Research Process}

The participants were asked to perform the evaluations in sequence. All of the evaluations were done in the Human-Computer Interaction (HCI) laboratory. The activities in the laboratory were as follows: (1) Usability testing, (2) system usability scale (SUS) survey, (3) heuristic evaluation, and (4) post-test interviews.

\section{1) Usability testing}

The myUnisa LMS was tested for ease of use as part of usability testing. The use of eye tracking assists the researcher to identify usability problems. Further, the usability of a system has an impact on the user's perception and therefore it was necessary to evaluate the effectiveness and satisfaction of the myUnisa LMS. Usability testing tasks were as shown in table II. The aim of T1 was to test if users can use the Wiki portal by adding a comment. In T2, we wanted to test if users can effectively use the discussion forum. T3 aimed to see if users could personalize settings to fit their preference needs. While in T4, we were checking whether supervisors could easily find a project.

\begin{tabular}{|c|c|c|}
\hline \multicolumn{3}{|c|}{$\begin{array}{c}\text { TABLE II } \\
\text { USABILITY TESTING TASKS }\end{array}$} \\
\hline Tasks & Aims & Descriptions \\
\hline T1 & $\begin{array}{l}\text { Testing the ability to } \\
\text { use Wiki portal }\end{array}$ & $\begin{array}{l}\text { Add a new comment on the Wiki } \\
\text { portal as follows. } \\
\text { 'Hello, world' }\end{array}$ \\
\hline T2 & $\begin{array}{l}\text { Testing the system's } \\
\text { ability to provide a } \\
\text { discussion forum or } \\
\text { collaborative learning } \\
\text { tools }\end{array}$ & $\begin{array}{l}\text { Add a new topic on the } \\
\text { discussion forum using the } \\
\text { subject heading indicated below. } \\
\text { 'What are e-Learning } \\
\text { Technologies?' }\end{array}$ \\
\hline T3 & $\begin{array}{l}\text { Testing the system's } \\
\text { ability of } \\
\text { customisation or } \\
\text { personalisation or } \\
\text { preference settings }\end{array}$ & $\begin{array}{l}\text { Customise the following features } \\
\text { to suit your preferences. } \\
\text { 1. Change language to: 'English } \\
\text { - United Kingdom' } \\
\text { 2. Change notifications to: 'Do } \\
\text { not send me notifications' }\end{array}$ \\
\hline T4 & $\begin{array}{l}\text { Testing the easiness to } \\
\text { find projects in order } \\
\text { for students to perform } \\
\text { tasks }\end{array}$ & $\begin{array}{l}\text { Look for projects and read aloud } \\
\text { (verbalise) the title of the } \\
\text { following project. } \\
\text { 'Agile Software Development } \\
\text { Adoption in South Africa' }\end{array}$ \\
\hline
\end{tabular}

\section{2) System usability scale (SUS) questionnaire}

The system usability scale (SUS) questionnaire was completed after the participants have completed the usability testing tasks. SUS questionnaire has an accepted set of questions that track the success metrics of a system very closely [16]. The participants rated each question using a 5-point Likert scale ranging from "strongly disagree" to "strongly agree" [27]. The analysis of SUS scores provides the researcher with an opportunity to identify the usability problems from supervisors' point of view.

\section{3) Heuristic evaluation}

The supervisors were given a set of heuristic evaluation criteria to evaluate the usability guidelines independently through the myUnisa LMS. There was no specific time limit to complete the evaluation but most of them completed within 30 minutes. Thirty-four (34) heuristic 
evaluation items were used for evaluation. After completing the evaluation, the participant was asked to participate in the post-test interviews.

\section{4) Post-test interviews}

The post-test interviews were used to obtain the participants' feedback, feelings and opinions about the system. Participants were asked questions as planned by the researcher and responses were captured. There were five questions aimed at gathering feedback based on (1) usability of myUnisa LMS, (2) content found on myUnisa LMS, (3) system capability in terms of communication between students and their peers, (4) system capability in terms of communication between students and supervisors, and (5) comments to add regarding the learning management system issues.

\section{FINDINGS}

The following performance metrics were identified as relevant to the study goals: Task success and time on task - (1) completed task within time frame and without assistance or (2) completed task within time frame and with assistance. Issues - problems experienced when performing the tasks. Post-test questionnaires - overall user satisfaction with the system.

All nine participants completed task 1 without assistance, and eight participants completed task 2 without assistance, for task 3 only two participants completed without assistance and for task 4, six participants completed without assistance. This means that most of the participants required assistance in completing tasks 3 and 4. This would be problematic for an ODL student working in isolation as it means that they would not have managed to complete the task. The average time on task was 453 in seconds, with the minimum time 240 in seconds and the maximum time 780 in seconds. This wide variation in completion time also indicates potential usability issues. The main usability issues included setting preferences on the site (identified in task 3 ) and finding a project feature on the site (task 4). Figure 1 depicts the results of the posttest questionnaire, which the participants completed after performing the usability testing tasks.

\section{SUS Scores}

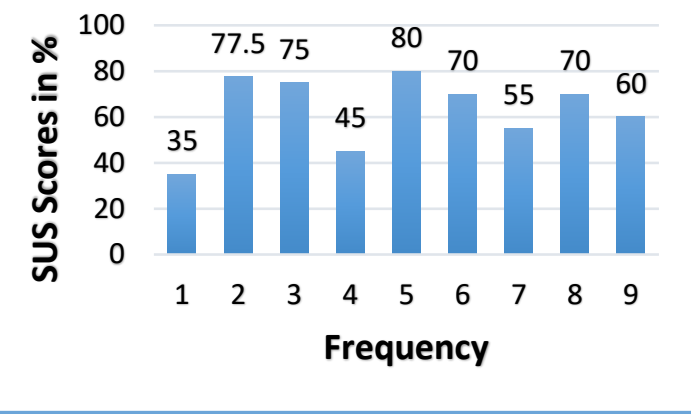

Figure 1. A SUS scores - the responses from each participant $(n=9)$

The average SUS scores with respect to the usability the myUnisa LMS is $63 \%$. The interpretation of the SUS scores is that less than $50 \%$ is not acceptable, between $50 \%$ and $70 \%$ is marginal and above $70 \%$ is acceptable. This means the LMS was found in the range of marginal to be acceptable. The marginal category assumes that the LMS platform requires some intervention in order to be acceptable.

Regarding the heuristic evaluation, the combined values for values for Agree and Strongly Agree, are as follows:

Simplicity of navigation, readability, organisation and structure of the content (73.3\%); Relevance of site content to the learner and the learning process $(74.1 \%)$; Clear learning goals, objectives and outcomes (55.6\%); Visibility of system status and content (72.2\%); Match between the system and the real world $(77.8 \%)$; Flexibility and efficiency of use $(63 \%)$; Learner control and freedom (44.4\%); Consistency and adherence to standards (72.2\%); Recognition rather than recall (59.3\%); Effectiveness of collaborative learning (75\%); Adaptive learning content (54.2\%). The total average of all the categories is $65.5 \%$. According to these heuristic evaluation scores, the LMS is in the category of acceptable (50-70\%) when using the SUS range. This means that the two methods provide the same overall result. The relatively lower scores of learner control and freedom $(44.4 \%)$ and adaptive learning content $(54.2 \%)$, resonate with the usability issues identified on setting preferences.

Considering the findings from the interviews, the participants' comments confirmed that the system was usable but not optimal. The issues with learner control and adaptivity were confirmed. Two participants suggested the inclusion of social interaction and more collaborative learning towards improving the learning experience. Based on the results of the study we recommend a list of updates to the proposed usability guidelines for learning 
management systems in the ODeL contexts. Previous studies conducted by Ssemugabi \& de Villiers [15] evaluated the usability of the Info3Net system, compared the results of experts with that of learners and found that those results correspond respectively and have concluded that the evaluation guidelines are appropriate for the web based learning (WBL) applications. Mtebe and Kissaka [8] proposed heuristics for evaluating the usability of LMSs and confirmed that they are valid for the African continent. This study is novel in considering the supervisors' view; it also contributes methodologically by triangulating the results from four different methods of data collection.

\section{DISCUSSION OF THE FINDINGS}

Our findings support the earlier finding by Ssemugabi \& De Villiers [15] that heuristics can be effective in evaluating LMS platforms. The overall findings from the usability testing, the SUS scores and the heuristic evaluation concurred in finding the system usable but not optimal. Therefore, the triangulation of the findings confirmed the usefulness of the usability guidelines. The results of the heuristic evaluation correspond with the interview results since the major problems identified through heuristic evaluation were also raised during the interviews.

The results of the triangulation provide us with the following recommendations for updating the myUnisa LMSs.

a) Clearly visualise course structure.

b) Increase the space for uploading learning materials.

c) Provide for Undo and Redo functionalities.

d) Improve consistency: the words and symbols should refer to the same concept throughout. e) Design communication tools to support collaborative learning.

f) Track system usage periodically.

g) Consider the use of emerging technologies like WhatsApp grouping, Facebook grouping to maximise student interaction, support and collaboration.

h) Provide the possibility to personalise the user interface.

i) Maximise personalised access to learning contents and allow the possibility to personalise the learning path.

Based on the status of the system and findings from the interviews we recommend that LMSs within ODeL institutions should be designed with consideration of emerging technologies including social interaction and collaborative learning.

\section{CONCLUSIONS}

In this study, we proposed and evaluated usability guidelines for the myUnisa LMS from the supervisors' perspective. Data collection was done through usability testing, heuristic evaluation, post-test questionnaires and interviews. The findings indicate that the heuristic evaluation results were in line with the results from the SUS survey, usability testing and the interviews. That study validated the appropriateness of the usability guidelines based on the triangulation of the findings from the four methods. Therefore, the guidelines are proposed as a discount method of evaluating an ODeL LMS. The guidelines can be improved by adding social media as a criterion. We also made recommendations for updating the myUnisa LMS based on the analysis of the results. More research is needed to consider the students' perspectives on the usability of the MyUnisa LMS again. Furthermore, future work should also evaluate the guidelines at other ODL institutions with different LMSs.

\section{APPENDIX}

\begin{tabular}{|l|l|l|}
\hline \multicolumn{3}{|c|}{ TABLE III } \\
\hline Criteria & Guidelines & References \\
\hline $\begin{array}{l}\text { Simplicity of navigation, } \\
\text { readability, organisation and } \\
\text { structure of the content }\end{array}$ & $\begin{array}{l}\text { Users should know where they are and have the option to select where to go next. The } \\
\text { navigational options are limited, so as not to overwhelm the user. The content of this website is } \\
\text { well organised and related information is placed together. Pages have the required navigation } \\
\text { buttons or hyperlinks. }\end{array}$ & {$[29,15,16,29,30]$} \\
\hline $\begin{array}{l}\text { Relevance of site content to the } \\
\text { learner and the learning process }\end{array}$ & The content should be relevant, current and appropriate to learners using myUnisa platform. & {$[15,16,29]$} \\
\hline $\begin{array}{l}\text { Clear learning goals, objectives } \\
\text { and outcomes }\end{array}$ & The goals, objectives and outcomes for learning encounters should be clear. & {$[15,16,22,3031]$} \\
\hline $\begin{array}{l}\text { Visibility of system status and } \\
\text { content }\end{array}$ & The website should provide appropriate and timely feedback and response to user-initiated actions. & {$[8,31,32]$} \\
\hline $\begin{array}{l}\text { Match between the system and } \\
\text { the real world }\end{array}$ & $\begin{array}{l}\text { Language usage in terms of phrases, symbols, and concepts is similar to that of users in their day- } \\
\text { to-day environment. Metaphor usage corresponds to real-world objects and concepts. }\end{array}$ & {$[8,31,32]$} \\
\hline Flexibility and efficiency of use & $\begin{array}{l}\text { The site caters for different levels of users, from novice to expert. The system is flexible to enable } \\
\text { users to adjust settings to suit themselves, i.e. to customise the system. }\end{array}$ & {$[8,31,32]$} \\
\hline
\end{tabular}




\begin{tabular}{|c|c|c|}
\hline Learner control and freedom & There are facilities for Undo and Redo. & {$[8 ; 15 ; 30 ; 31]$} \\
\hline $\begin{array}{l}\text { Consistency and adherence to } \\
\text { standards }\end{array}$ & $\begin{array}{l}\text { The same concepts, words, symbols, situations, or actions refer to the same thing. Common } \\
\text { platform standards are followed. }\end{array}$ & {$[8 ; 15 ; 31 ; 32]$} \\
\hline Recognition rather than recall & $\begin{array}{l}\text { Objects to be manipulated, options for selection, and actions to be taken are visible. The user does } \\
\text { not need to recall information from one part of a dialogue to another. Instructions on how to use } \\
\text { the system are retrievable. }\end{array}$ & {$[8,31,32]$} \\
\hline $\begin{array}{l}\text { Effectiveness of collaborative } \\
\text { learning }\end{array}$ & $\begin{array}{l}\text { Facilities and activities encourage learner-learner and learner-teacher interactions including both } \\
\text { asynchronous and synchronous communication, such as e-mail, discussion forums, wikis and } \\
\text { chats. There are tools for communicating within a group for example, forums, e-mail, wikis and } \\
\text { chats. }\end{array}$ & {$[15,16,29,22]$} \\
\hline Adaptive learning content & $\begin{array}{l}\text { Learners have some freedom to direct their learning, either individually or collaboratively, and } \\
\text { have a sense of ownership of it. Learners have some control of the content, sequence and how it is } \\
\text { learned. Educators can customise learning artefacts to the individual learner. }\end{array}$ & {$[15,16,22,32]$} \\
\hline
\end{tabular}

\section{ACKNOWLEDGEMENT}

This work is based on the research supported by the South African Research Chairs Initiative of the Department of Science and Technology and National Research Foundation of South Africa (Grant No. 98564).

\section{REFERENCES}

[1] UNISA, “Open distance learning policy,” 2015.

[2] M. Elbeck and B. J. Mandernach, "Journals for computermediated learning: Publications of value for the online educator," Int. Rev. Res. Open Distance Learn., vol. 10, no. 3 , pp. 1-20, 2009.

[3] O. R. E. Pereira and J. J. P. C. Rodrigues, "Survey and analysis of current mobile learning applications and technologies," ACM Comput. Surv., vol. 46, no. 2, pp. 1-35, Nov. 2013.

[4] J. A. Wiid, M. C. Cant, and S. M. Kallier, "The perceptions of students on the use of social networking systems as a teaching tool in ODL institutions," Int. Bus. Econ. Res. J., vol. 14, no. 1, pp. 27-38, 2015.

[5] K. A. Maboe, "Use of online interactive tools in an open distance learning context: Health studies students' perspective," Heal. SA Gesondheid, vol. 22, pp. 221-227, 2017.

[6] K. Maboe, Z. Nkosi, and M. Makoe, "Prospects and challenges of learners On-line discussion forum interaction in an ODL (Open Distance Learning) institution," J. Heal. Sci., vol. 1, no. 2013, pp. 12-20, 2013.

[7] B. I. Fozdar, "Open and distance learning (ODL): A strategy of development through its potential role in improving science \& technology knowledge," Int. J. Emerg. Technol. Learn., vol. 10, no. 2, pp. 9-16, 2015.

[8] J. S. Mtebe and M. M. Kissaka, "Heuristics for evaluating usability of Learning Management Systems in Africa," in 2015 IST-Africa Conference, 2015, pp. 1-13.

[9] S. Alharbi and S. Drew, "Using the Technology Acceptance Model in Understanding Academics' Behavioural Intention to Use Learning Management Systems," Int. J. Adv. Comput. Sci. Appl., vol. 5, no. 1, pp. 143-155, 2014.

[10] D. J. Keegan, “On defining distance education,” Distance Educ., vol. 1, no. 1, pp. 13-36, 1980.

[11] M. Jakovljevic, S. Buckley, and M. Bushney, "Well-designed communities of practice ( CoPs ) in the ODeL environment: students'perspective," Indep. J. Teach. Learn., vol. 9, no. 1, pp. 44-62, 2014

[12] S. Nqubane-Mokiwa, "Implications of the University of South Africa's (UNISA) shift to Open Distance e-Learning on Teacher Education," Aust. J. Teach. Educ., vol. 42, no. 9, pp. 111-124, 2017.

[13] W. R. Watson and S. L. Watson, "What are learning management systems, what are they not, and what should they become?," TechTrends, vol. 51, no. 2, pp. 28-34, 2007.

[14] 9241-11:2018 ISO, "Ergonomics of human-system interaction - Part 11: Usability: Definitions and concepts (ISO 9241 11:2018)," Br. Stand. Inst. 2018, 2018.

[15] S. Ssemugabi and R. de Villiers, "A comparative study of two usability evaluation methods using a web-based e-learning application," in Proceedings of the 2007 annual research conference of the South African institute of computer scientists and information technologists on IT research in developing countries - SAICSIT '07, 2007, pp. 132-142.

[16] S. Ssemugabi and M. R. De Villiers, "Effectiveness of heuristic evaluation in usability evaluation of e- learning applications in higher education," South African Comput. J., vol. 45 , pp. $26-39,2010$.

[17] D. Quiñones and C. Rusu, "How to develop usability heuristics: A systematic literature review," Comput. Stand. Interfaces, vol. 53, pp. 89-122, Aug. 2017.

[18] D. Quiñones, C. Rusu, and V. Rusu, "A methodology to develop usability/user experience heuristics," Comput. Stand. Interfaces, vol. 59, no. March, pp. 109-129, 2018.

[19] J. Nielsen and R. Molich, "Heuristic Evaluation of user interfaces," in CHI '90 Proceedings of the SIGCHI Conference on Human Factors in Computing Systems, 1990, no. April, pp. 249-256.

[20] N. Abdollah et al., "Formative usability evaluation of a webbased lecture capture \& learning management solution," in Proceedings - 2014 3rd International Conference on User Science and Engineering: Experience. Engineer. Engage, $i$ USEr 2014, 2015, pp. 137-142.

[21] S. Çelik, "Development of usability criteria for e-learning content development software," Turkish Online J. Distance Educ., vol. 13, no. 2, pp. 336-345, 2012.

[22] J. Nyang'or, R. De Villiers, and S. Ssemugabi, "A framework for usability evaluation of an offline e-learning tutorial and its application in usability testing," in EdMedia: World Conference on Educational Media and Technology, 2013, pp. 1097-1105. 
[23] A. R. Hevner, S. T. March, J. Park, and S. Ram, "Design science in information systems research," $M I S Q$, vol. 28, no. 1, pp. 75-105, 2004

[24] A. R. Hevner, S. T. March, J. Park, and S. Ram, "Essay in Information Design Science systems," Manag. Inf. Syst. Res. Center, Univ. MinnesotaStable, vol. 28, no. 1, pp. 75-105, 2011.

[25] K. Peffers, T. Tuunanen, M. Rothenberger, and S. Chatterjee, "A design science research methodology for information systems research," J. Manag. Inf. Syst., vol. 24, no. 3, pp. 4578, 2007.

[26] S. Gregor and A. R. Hevner, "Positioning and presenting design science types of knowledge in design science research," MIS Q., vol. 37, no. 2, pp. 337-355, 2013.

[27] J. Brooke, "SUS: A Retrospective," J. Usability Stud., vol. 8, no. 2, pp. 29-40, 2013

[28] S. Ssemugabi and M. R. De Villiers, "Effectiveness of heuristic evaluation in usability evaluation of e- learning applications in higher education," South African Comput. J., vol. 45, no. July, pp. 26-39, 2010.

[29] M. Toit and C. Bothma, "Evaluating the usability of an academic marketing department's website from a marketing student' s perspective," Africa (Lond)., vol. 5, no. 1, pp. 2538, May 2009.

[30] R. Medina-Flores and R. Morales-Gamboa, "Usability Evaluation by Experts of a Learning Management System," Rev. Iberoam. Tecnol. del Aprendiz., vol. 10, no. 4, pp. 197203, Nov. 2015.

[31] J. Nielsen, "Enhancing the explanatory power of usability heuristics," in Conference companion on Human factors in computing systems - CHI '94, 1994, pp. 152-158.

[32] N. M. Sabri, H. Mohamed, G. Y. Soon, and Y. H. M. Yusof, "A Quantitative Approach in the Usability Evaluation of A Courseware," J. Next Gener. Inf. Technol., vol. 4, no. 2, pp. 29-38, 2013.

[33] C. Ardito et al., "An approach to usability evaluation of elearning applications," Univers. Access Inf. Soc., vol. 4, no. 3, pp. 270-283, Mar. 2006. 